\title{
ESTRESSE DE TRANSPORTE EM CASCUDOS AMAZÔNICOS ORNAMENTAIS Cochliodon sp. (L145) E Hypostomus sp. (L28) (LORICARIIDAE)
}

\author{
Mikaelle de Souza NEVES1, Márcia Valéria Silva COUTO1, Natalino Costa SOUSA¹, Rudã \\ Fernandes Brandão SANTOS2, Marcos TAVARES-DIAS³ e Rodrigo Yudi FUJIMOTO1
}

\section{RESUMO}

\begin{abstract}
Neste estudo avaliou-se a resposta hematológica dos acaris ornamentais Cochliodon sp. (L145) e Hypostomus sp. (L28) ao estresse de transporte. Foram determinados o eritrograma, leucograma, trombograma, níveis de glicose e proteínas plasmáticas totais (PPT) em 0, 6, 24, 48 e 72 horas após um transporte simulado de 3 horas. Para o perfil hematológico basal o sangue foi coletado imediatamente no local de captura dos peixes sob o mínimo de estresse possível. Cochliodon sp. mostrou redução no número de eritrócitos totais após 6 e 24 horas do estresse de transporte, e aumento da glicose após 6 horas. Em Hypostomus sp. houve hipoglicemia após 6 horas de transporte e ao mesmo tempo aumento do volume corpuscular médio (VCM) pós estresse. Neste estudo observou-se diferenças na resposta ao estresse entre os peixes estudados, pois Hypostomus sp. apresentou maior resistência em comparação a Cochliodon sp. quando submetido ao estresse de transporte.
\end{abstract}

Palavras-Chave: acari; hematologia; hipoglicemia; bacia do rio Guamá

\section{TRANSPORT STRESS IN ORNAMENTAL AMAZONIAN ARMORED CATFISHES Cochliodon sp. (L145) AND Hypostomus sp. (L28) (LORICARIIDAE)}

\begin{abstract}
This study evaluated the hematological response of ornamental Amazon plecos Cochliodon sp. (L145) and Hypostomus sp. (L28) subjected to transportation conditions. The erythrogram, leukogram, thrombogram, glucose and total plasmatic proteins (TPP) were determined at $0,6,24$, 48 and 72 hours after 3-hours simulated transportation. For basal hematological profile, the blood was collected immediately after stress induction. Cochliodon sp. showed reduction in total erythrocyte number after 6 and 24 hours post-transport, and an increase in the glucose level after 6 hours. Hypoglycemia were observed at 6 hours post-transport withal an increase of the Mean Corpuscular Volume (MCV) for Hypostomus sp. Thus, Hypostomus sp. showed higher resistance compared to Cochliodon sp. under transport stress.
\end{abstract}

Key words: pleco; hematology; hypoglycemia; Guamá river basin

\footnotetext{
Artigo Científico: Recebido em 17/03/2016 - Aprovado em 07/10/2016

${ }^{1}$ Laboratorio de Aquicultura-Empresa Brasileira de Pesquisa Agropecuária (EMBRAPA-SE). Av. Beira Mar, 325, Caixa postal 44-CEP: 49025-040-Aracaju-SE-Brasil.e-mail: mikasneves03@gamil.com,vallcouto18@hotmail.com, ryfujim@hotmail.com (autor correspondente), natal159@yahoo.com.br

2Departamento de Bioquímica-Centro de Ciências Biológicas- Universidade Federal de Pernambuco (UFPE). Avenida Prof. Moraes Rego, s/n, Cidade Universitária, CEP: 50670-420, Recife-PE-Brasil.e-mail: ruda_fernandes@hotmail.com; ${ }^{3}$ Empresa Brasileira de Pesquisa Agropecuária (EMBRAPA-AM). Rodovia Juscelino Kubistcheck, Km 5, $n^{\circ} 2.600$, caixa postal 10-CEP: 68903-419, Macapá-AP-Brasil.e-mail: marcos.tavares@embrapa.br
}

Bol. Inst. Pesca, São Paulo, 42(4): 749-758, 2016 Doi: 10.20950/1678-2305.2016v42n4p749 


\section{INTRODUÇÃO}

A captura de peixes ornamentais movimenta um comércio lucrativo nos estados do Pará e Amazonas, principais exportadores, gerando aproximadamente 4 milhões de dólares no ano de 2007 (IBAMA, 2008; TORRES et al., 2008). Essa procura por peixes ornamentais amazônicos vem gerando empregos diretos e indiretos, tornando se atividade principal e fonte de renda para muitas famílias ribeirinhas que se dedicam parcial ou integralmente a captura desses peixes (CHAO, 2001; PRANG, 2001; TORRES et al., 2008).

Dentre as espécies comercializadas, os indivíduos pertencentes a família Loricariidae apresenta uma grande demanda de mercado, principalmente da Europa e Estados Unidos (CHAO et al., 2001; TORRES, 2007; RIBEIRO et al., 2008). Essas espécies possuem uma dificuldade inerente de identificação, assim utiliza-se o código L para identificar indivíduos que mesmo sem classificação taxonômica concluída, são comercializados (CAMARGO et al., 2012).

A elevada demanda por determinadas espécies de peixes assim como a falta de identificação taxonômica correta, ocasiona uma captura desordenada, condições de transporte, manutenção e manejo pós-captura inadequadas provocando assim altas mortalidades (GOMES et al., 2003), cujas causas são atribuídas a diversas condições causadoras de estresse (SALARO et al., 2003) as quais reduzem a produção e aumentam os custos da exploração.

O transporte desses peixes é um fator de estresse, pois as condições inadequadas a qual são submetidos ocasionam quebra da homeostasia e diminuição da resistência, que por consequência os torna mais susceptíveis as infestações parasitárias e infecções bacterianas, podendo ocasionar a morte dos animais (LIM et al., 2003). Nesse sentido a hematologia é uma ferramenta importante para a determinação de sinais de estresse (RANZANI-PAIVA e SILVA-SOUZA, 2004), podendo ser utilizada como indicador e consequentemente adequar manejos espécieespecíficos como no caso do transporte.

Portanto, este estudo tem como objetivo avaliar e comparar as respostas hematológicas dos Loricarídeos amazônicos ornamentais, o
Cochliodon sp. (L145) e Hypostomus sp. (L28) submetidos ao estresse de transporte.

\section{MATERIAL E MÉTODOS}

Foram capturados 60 espécimes de acari-pleco (Cochliodon sp.) conhecido nas exportadoras como L145 $(32,77 \pm 6,20$ g e comprimento $12,21 \pm 0,8 \mathrm{~cm})$ e 60 espécimes de acari-picoto (Hypostomus sp.) conhecidos como L28 $(38,5 \pm 4,8 \mathrm{~g}$ e $15,44 \pm 3,0 \mathrm{~cm})$ na bacia do Rio Guamá (S 01³4'04.6" W $\left.47^{\circ} 01^{\prime} 50.3^{\prime \prime}\right)$, município de Capitão Poço, estado do Pará (Brasil), com auxílio de pescadores locais. Os espécimes foram mantidos em tanques de tela submersos no próprio rio, até que se completasse o lote e diminuísse o estresse de captura. Então, após aproximadamente 10 dias, realizou-se as coletas sanguíneas em dez Cochliodon sp. e dez Hypostomus sp. "in loco", para a determinação do hemograma basal, antes da realização do estresse de transporte.

No momento da captura, assim como no período de aclimatação, foram mensuradas as seguintes variáveis físico e químicas da água: oxigênio dissolvido e temperatura (Oxygen Meter Lt Lutron DO-5519), pH (Aparelho Quimis ${ }^{\circledR}$ Q400BC/BD) e condutividade elétrica (YSI model 30). Posteriormente replicadas em laboratório para impedir variações de estresse decorrente da qualidade de água.

As coletas sanguíneas foram realizadas por punção caudal com o auxílio de seringas e agulhas previamente umedecidas com EDTA (10\%). Esse procedimento foi realizado ainda no local de captura imediatamente após a retirada dos espécimes dos referidos tanques de manutenção. Este procedimento teve duração média 30 segundos para cada indivíduo. Posteriormente separou-se os demais exemplares em grupos de 10, totalizando 5 grupos de Cochliodon sp. e 5 grupos de Hypostomus sp. Cada grupo foi embalado em sacos plásticos de $20 \mathrm{~L}$ de capacidade, com $6 \mathrm{~L}$ de água, correspondendo $1 / 3$ do seu volume, os outros $2 / 3$ foram preenchidos com ar. Estes sacos plásticos foram amarrados e transportados de veículo até o Laboratório de Ictioparasitologia e Piscicultura da UFPA, de forma a simular o processo de comercialização destes peixes na região. A embalagem, densidade e período de transporte, foram realizados de 
acordo com as informações dos pescadores locais. Ao chegarem ao laboratório, os peixes foram distribuídos em caixas de água de 300 L com sistema de recirculação, os quais foram aclimatados por cerca de 20 minutos, antes da primeira amostragem sanguínea pós estresse $(0 \mathrm{~h})$. As demais amostras sanguíneas foram coletadas as 6, 24, 48 e 72 horas pós estresse, sendo que em cada tratamento utilizou-se 10 peixes.

Em cada amostra de sangue foi determinado o nível de glicose sanguínea $\left(\mathrm{mg} \mathrm{dL}^{-1}\right)$ utilizando o medidor automático Prestige IQ 50, o hematócrito (\%) foi determinado pelo método de microhematócrito (GOLDENFARB et al., 1971), a hemoglobina $\left(\mathrm{g} \mathrm{dL}^{-1}\right)$ pelo método da cianometahemoglobina e leitura em aparelho Celm 500 e Celm 550 (Quimis ${ }^{\circledR}$, Brasil) e a contagem de eritrócitos totais $(\mu \mathrm{L})$ em câmara de Neubauer. De posse desses dados de eritrócitos, hematócrito e hemoglobina foram calculados os índices hematimétricos (VALLADA, 1999): Volume Corpuscular Médio (VCM), Hemoglobina Corpuscular Média (HCM) e Concentração de Hemoglobina Corpuscular Média (CHCM). Para a determinação dos níveis de proteína plasmática total ( $\mathrm{g} \mathrm{dL}^{-1}$ ) utilizou-se refratômetro (Quimis ${ }^{\circledR}$ ). Extensões sanguíneas foram confeccionadas, secas ao ar e coradas pancromicamente (ROSENFELD, 1947) para a contagem de leucócitos e trombócitos totais (TAVARES-DIAS e MORAES, 2006) e contagem diferencial de leucócitos. Os procedimentos de análises sanguíneas foram realizados igualmente em todas as etapas para determinar as características padrões e posteriores ao estresse de transporte estabelecido.

Os dados foram submetidos ao teste de normalidade e posteriormente à análise de variância e quando $F$ foi significativo $(p<0,05)$ realizou-se o teste de Tukey para comparação das médias $(\mathrm{p}<0,05)$.

\section{RESULTADOS}

As variáveis físico e químicas da água, em laboratório, foram semelhantes aos valores encontradas no habitat natural das espécies, com valores médios de oxigênio dissolvido igual a $6,3 \pm 0,8 \mathrm{mg} \mathrm{L}^{-1}$; $\mathrm{pH} 6,4 \pm 0,4$; condutividade elétrica $22,8 \pm 0,2 \mu \mathrm{S} \mathrm{cm}^{-1}$ e temperatura $25 \pm 1,2{ }^{\circ} \mathrm{C}$.

As duas espécies estudadas responderam diferentemente ao estresse de transporte. $\mathrm{O}$ Cochliodon sp., apresentou hiperglicemia 6 horas pós-estresse de transporte, diferente do Hypostomus sp., que apresentou uma hipoglicemia após 6 horas (Figura 1A). Um padrão de resposta pôde ser observado para hematócrito em Cochliodon sp. com aumento desse parâmetro até 72 horas pós estresse, que não é observado no Hypostomus sp. (Figura 1B). O inverso ocorreu nas proteínas plasmáticas totais, no qual observou-se um padrão de aumento constante até 72 horas pós estresse para o Hypostomus sp. não sendo observado o mesmo padrão para o Cochliodon sp. (Figura 1C). Isoladamente estas espécies também apresentaram diferenças nos parâmetros do eritograma, sendo que para Cochliodon sp. observou-se redução na quantidade de eritrócitos até as 24 horas (Figura 2A) aumentando após esse período. Por outro lado os eritroblastos apresentaram uma elevação às $6 \mathrm{~h}$, com retorno aos valores basais às 24 horas permanecendo constante até às 72 horas (Figura 2B), com a redução da hemoglobina até às 24 horas elevandose ao final das 72 horas (Figura 2C) e o HCM apresentou redução até 72 horas (Figura 2D). Estes parâmetros não mostraram diferença para $\mathrm{o}$ Hypostomus sp., porém observou-se para essa espécie aumento do VCM até 6 horas com posterior redução até o final de 72 horas (Figura $2 \mathrm{E})$, sendo que não foram observadas diferenças nos valores de CHCM (Figura 2F) para as espécies após o estresse de transporte. 

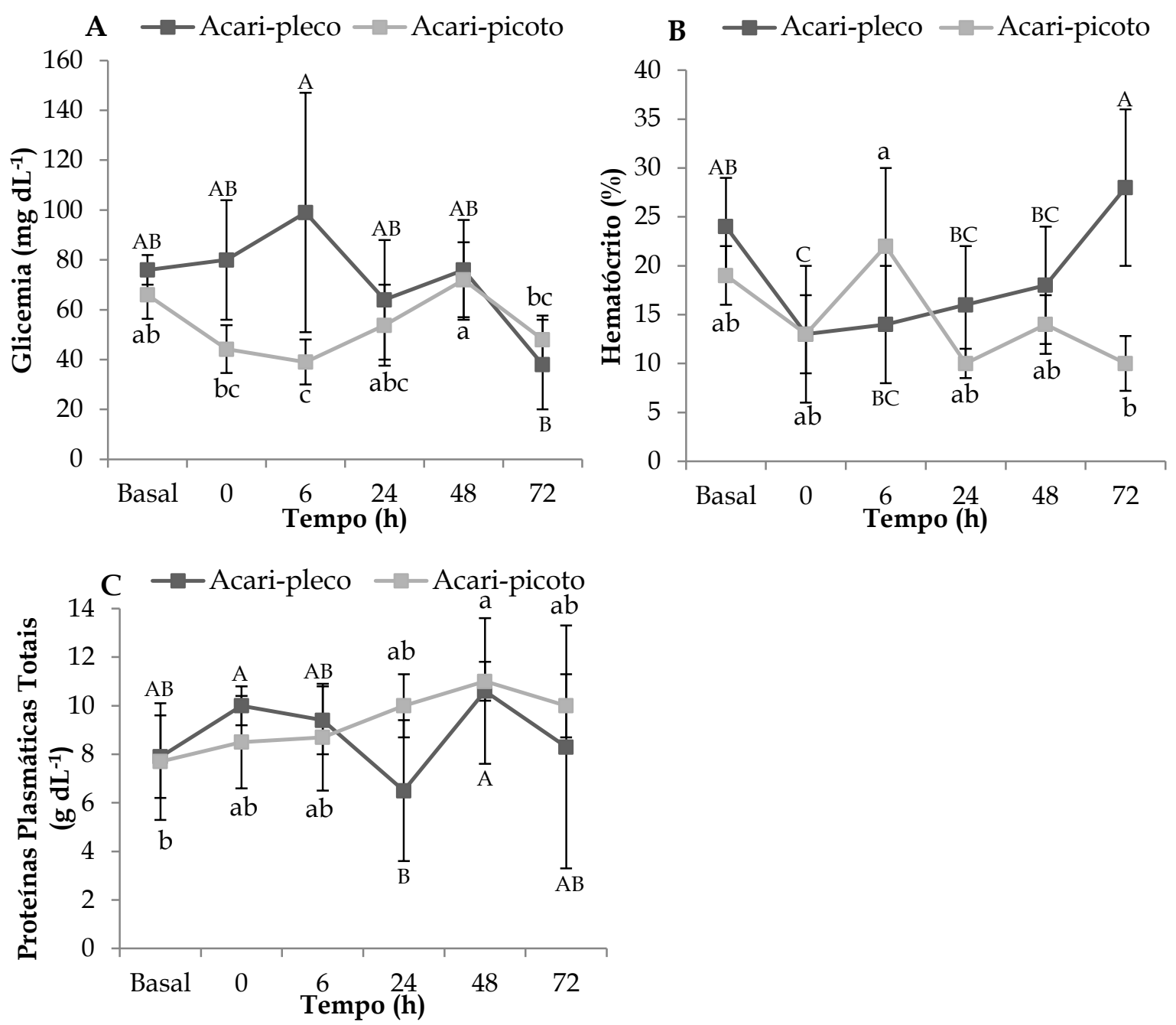

Figura 1. Valores hematológicos das espécies Cochliodon sp. (acari-pleco) e Hypostomus sp. (acari-picoto) submetidos ao estresse de transporte. Glicemia (A); Hematócrito (B) e Proteínas plasmáticas Totais (C). Média \pm desvio padrão $(n=60)$, valores nas box-splot com letras iguais não diferem pelo teste de Tukey ( $p>0,05)$, letra maiúscula representa Cochliodon sp. em minúscula Hypostomus sp.

Com relação às respostas no leucograma e trombrograma, observou-se diferença para o Hypostomus sp., com elevação dos trombócitos (Figura 3A), leucócitos totais (Figura 3B), linfócitos (Figura 3C), monócitos (Figura 3D) às 48 horas, com retorno aos valores basais às 72 horas. Já para o neutrófilo, o padrão de resposta entre os acaris é semelhante, com elevação dos valores nas primeiras horas após o estresse para o Cochliodon sp., com redução ao final de 72 horas, porém com um atraso de reposta no Hypostomus sp. (Figura $3 E)$, que apresenta uma elevação nos valores após 6 horas após o estresse. 

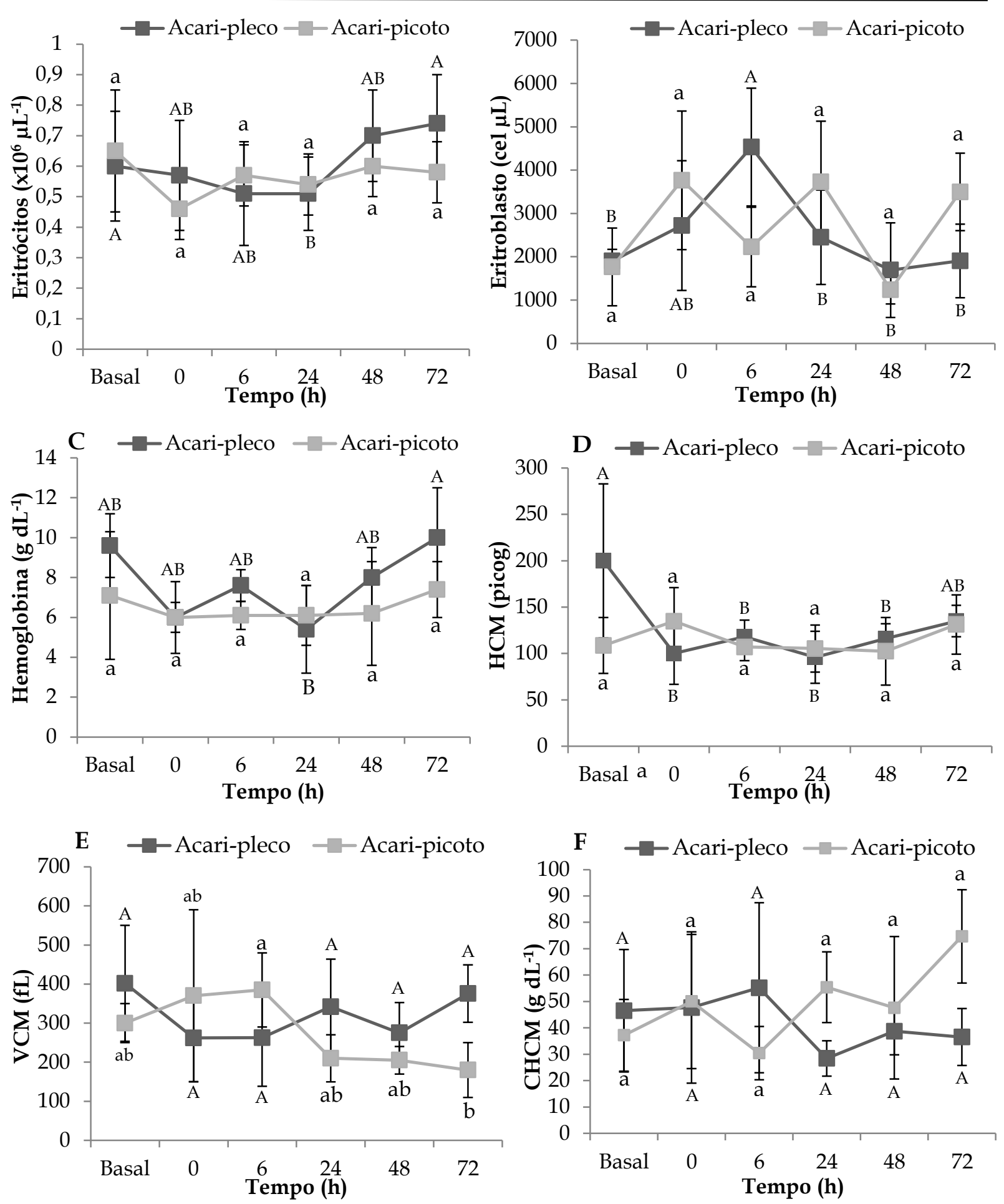

Figura 2. Parâmetros eritrocitários em Cochliodon sp. (acari-pleco) e Hypostomus sp. (acari-picoto) ao estresse de transporte. A) Eritrócitos; B) Eritroblastos; C) Hemoglobina Total; D) Hemoglobina Corpuscular Média (HCM); E) Volume Corpuscular Médio (VCM) e F) Concentração de Hemoglobina Corpuscular Média $(\mathrm{CHCM})$. Média \pm desvio padrão $(\mathrm{n}=60)$, valores dos box-splots com letras iguais não diferem pelo teste de Tukey $(\mathrm{p}>0,05)$, letra maiúscula representa resposta da espécie Cochliodon sp. em minúscula resposta da espécie Hypostomus sp. 

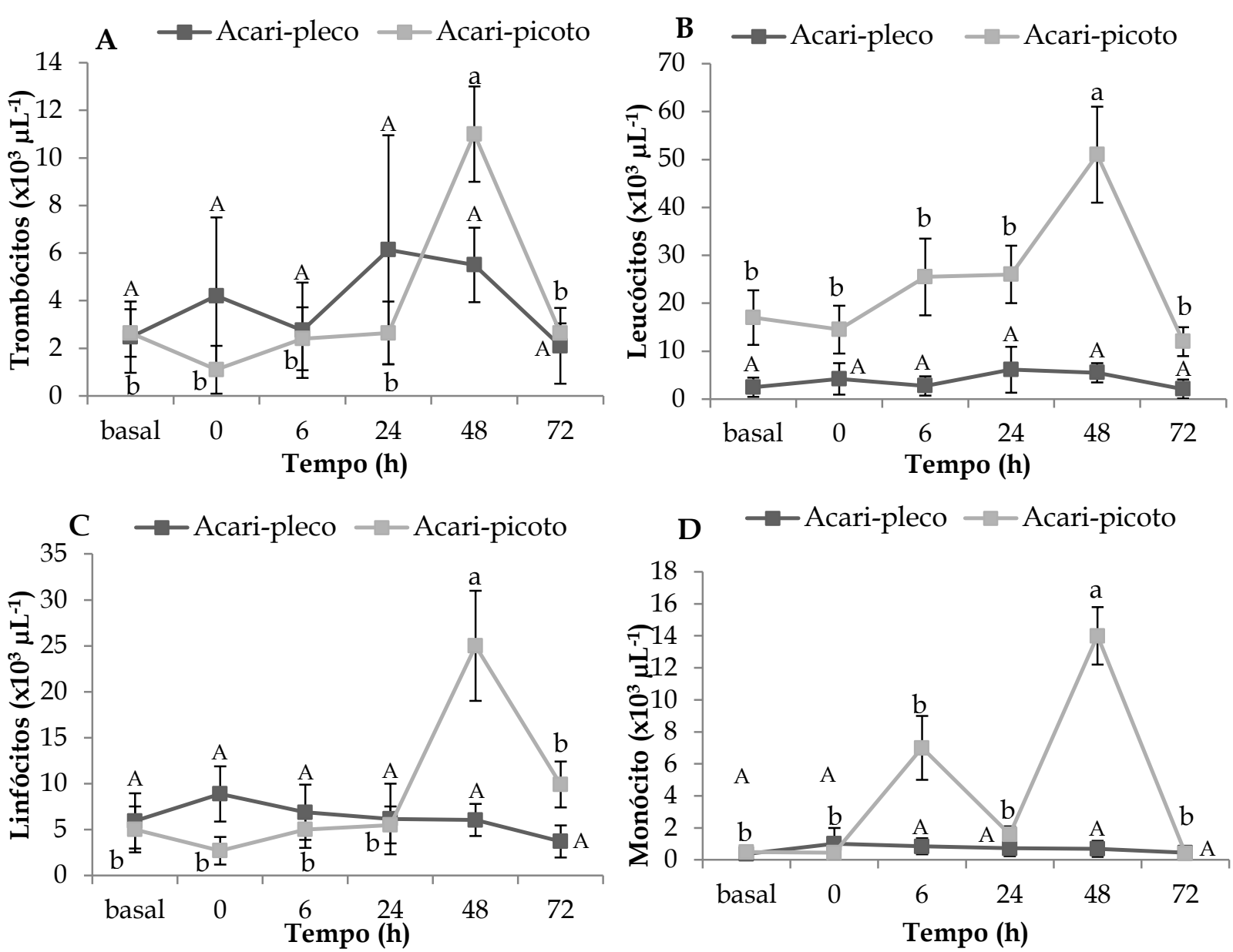

D $\rightarrow$ Acari-pleco - Acari-picoto
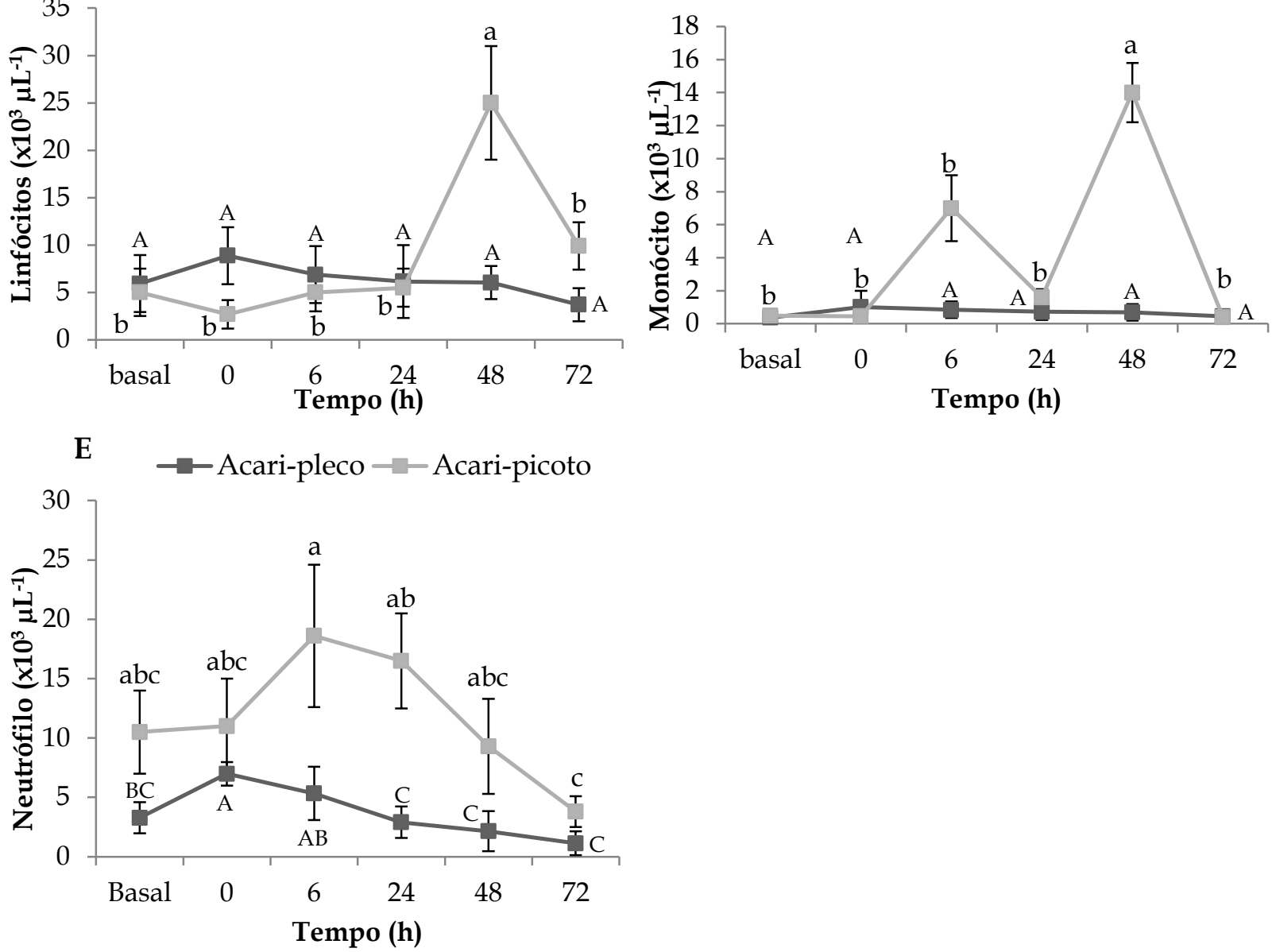

Figura 3. Parâmetros leucocitários e trombocíticos em Cochliodon sp. (acari-pleco) e Hypostomus sp. (acaripicoto). submetidos ao estresse de transporte. A) Trombócitos totais; B) Leucócitos totais; C) Linfócitos; D) Monócitos e E) neutrófilos. Média \pm desvio padrão $(n=60)$, valores dos box-splots com letras iguais não diferem pelo teste de Tukey $(p>0,05)$, letra maiúscula representa resposta da espécie Cochliodon sp. em minúscula resposta da espécie Hypostomus sp. 


\section{DISCUSSÃO}

A condição de transporte inadequado é um fator estressante, pois pode ocasionar a diminuição da resistência dos peixes, que por consequência ficam mais susceptíveis às infestações parasitárias e infecções bacterianas, podendo ocasionar a morte dos animais (LIM et al., 2003). Assim, compreender os mecanismos de resposta do estresse de transporte é importante para estabelecer um manejo adequado para cada espécie de peixe.

Nesse cenário, a mensuração dos níveis de glicose sanguínea é um importante parâmetro para diagnosticar estresse em peixes (ACERETE et al., 2004; BARBIERI e BONDIOLI, 2013). No presente estudo houve hiperglicemia plasmática em Cochliodon sp. após 6 horas de estresse, e o inverso, uma hipoglicemia foi observada para Hypostomus sp. no mesmo período.

A hiperglicemia observada em Cochliodon sp. é uma resposta fisiológica secundária clássica à vários estímulos estressores (BARTON, 2000; URBINATI e CARNEIRO, 2001; ACERETE et al., 2004; TAVARES-DIAS e MORAIS, 2004). Essa hiperglicemia está relacionada com a liberação do cortisol e catecolaminas que são liberados como respostas primárias ao agente estressor. Essa liberação de glicose tem como objetivo principal dispor energia, principalmente, para o sistema nervoso e músculos, como preparo para a fuga ou enfrentamento da situação estressante (BULLIS, 1993; WENDELAAR-BOGA, 1997; MOMMSEN et al., 1999), permitindo que o organismo se adapte a esta situação, através do estabelecimento de um novo patamar de equilíbrio orgânico (SCHALCH et al., 2005).

A hipoglicemia frente a situações estressantes não é relatada na literatura, exceto quando relacionada com contaminantes químicos como o chumbo, indicando estresse crônico (WINKALER et al., 2001). Assim, o resultado encontrado pode estar relacionado com uma maior resistência de Hypostomus sp. ao estresse, demonstrando uma resposta atrasada em relação a Cochliodon sp., pois observou-se hiperglicemia somente em 48 h pós estresse.

Assim como a glicemia, a disfunção osmorregulatória é característica de estresse podendo ser observada por uma hemoconcentração ou hemodiluição (HOUSTON et al., 1996; PIMPÃO, 2006) e as alterações na concentração de hemoglobina e hematócrito acompanhadas por hiperglicemia e diminuição do número de linfócitos são respostas relacionadas ao estresse ocasionado por manejo inadequado (URBINATI e CARNEIRO, 2001).

$\mathrm{Na}$ análise da hora Zero $(0 \mathrm{~h})$, Cochliodon sp. apresentou hemoconcentração, caracterizada pela manutenção da quantidade de eritrócitos, hemoglobina, e a diminuição do HCM e hematócrito. Tal quadro foi complementado com a concentração de proteínas plasmáticas totais, o que pode ser um reflexo da perda de água, por possíveis disfunções osmorregulatórias, já que o VCM não apresentou diferença significativa entre os períodos investigados. Sendo que 24 horas após o estresse, Cochliodon sp. apresentou um processo característico de anemia, com diminuição do número de eritrócitos, hemoglobina, HCM e hematócrito. Porém, esse processo possivelmente foi uma resposta do peixe para adaptar-se ao estresse de transporte e não por estar anêmico. Além disso, anteriormente a esse período observou-se também aumento na quantidade de eritroblastos circulantes as 0 e 6 horas após o estresse, talvez com o objetivo de tentar superar a situação estressante e reestabelecer o fornecimento adequado do oxigênio aos tecidos para reaver a homeostase (RANZANI-PAIVA e SILVA-SOUZA, 2004).

Já o eritrograma de Hypostomus sp. apresentou diferenças quando comparado ao observado para Cochliodon sp., com aumento apenas no VCM e hematócrito, após 6 horas de estresse. Além disso, houve elevação nos valores de proteínas plasmáticas totais a partir de 0 h e 48 horas em Cochliodon sp. e as 48 horas em Hypostomus sp. Este quadro de disfunção osmorregulatória pode ter causado o deslocamento de água do plasma sanguíneo para o interior dos eritrócitos aumentando assim o VCM, o que acarretou o aumento também do hematócrito e, por consequência, uma concentração de proteínas totais no plasma sanguíneo no mesmo período observado pósestresse onde o peixe tenta reestabelecer sua homeostase (PIMPAO, 2006; EL-SAYED et al., 2007).

Os leucogramas de Hypostomus sp. e de 
Cochliodon sp. foram relativamente similares ao descrito para diversas espécies de peixes quando em situação de estresse, porém a linfocitopenia que é uma das respostas leucocitárias indicadoras de estresse em peixes (TAVARES-DIAS et al., 2001; MARTINS et al., 2002; CARNEIRO et al., 2002; SILVEIRA-COFFIGNY et al., 2004; URBINATI e CARNEIRO, 2004; ABREU e URBINATI, 2006) decorrente de um processo de imunossupressão (CAMPBELL, 2004), não foi observada em qualquer uma das espécies estudadas.

Em períodos diversos, foi observada neutrofilia em Cochliodon sp., e uma leucocitose devido a neutrofilia, linfocitofilia e monocitofilia em Hypostomus sp. Os neutrófilos contribuem na defesa contra infecções devido a sua capacidade fagocítica, sendo os primeiros leucócitos a realizar diapedese. Já essa leucocitose é uma resposta a um estímulo estressor que causa contração esplênica devido ao efeito simpático e consequente liberação de leucócitos para a circulação sanguínea (TAVARES-DIAS et al., 2001; FUJIMOTO et al., 2007).

\section{CONCLUSÕES}

O estresse de transporte de 3 horas desencadeou alterações hematológicas moderadas e distintas para Hypostomus sp. e Cochliodon sp., possivelmente o Hypostomus sp. possui uma maior resistência em comparação ao Cochliodon sp. Recomenda-se que após o manejo de transporte de ambas as espécies de acaris seja utilizado um período de aproximadamente 48 horas para a recuperação, visando assegurar uma maior higidez e sobrevivência dos peixes, antes de sua comercialização. Porém, novas pesquisas são necessárias para verificar o quadro hematológico dos acaris submetidos a estresse de transportes em tempos mais prolongados, pois estas espécies também são exportadas.

\section{AGRADECIMENTOS}

Os autores agradecem ao $\mathrm{CNPq}$ pelo financiamento ao projeto e a CAPES pela bolsa concedida ao primeiro autor.

\section{REFERÊNCIAS}

ABREU, J.S.; URBINATI, E.C. 2006 Physiological responses of matrinxã Brycon amazonicus fed different levels of vitamin $C$ and submitted to air exposure. Acta Amazonica, 36(4): 519-524.

ACERETE, L.; BALASCH, J.C.; ESPINOSA, E.; JOSA A.; TORT, L. 2004 Physiological response in Eurasian Perch (Perca fluviatilis) subjected to stress to transport and handling. Aquaculture, 237(4): 167-178.

BARBIERI, E.; BONDIOLI, A.C.V. 2013 Acute toxicity of ammonia in Pacu fish (Piaractus mesopotamicus, Holmberg, 1887) at different temperatures levels. Aquaculture Research, 46(3): 565-571

BARTON, B.A. 2000 Salmonid fishes differ in their cortisol and glucose responses to handling and transport stress. North American Journal Aquaculture, 62(1): 12-18.

BULLIS, R.A. 1993 Clinical pathological of temperature freshwater and estuarine fishes. In: STOSKOPF, M.K. (ed). Fish medicine. Philadelphia: W.B. Saunders Company. p. 232239.

CAMARGO, M.; JUNIOR, H.G.; PY-DANIEL, L.R. 2012 Acaris Ornamentais do Médio Rio Xingu: Ornamental Plecos of the Middle Xingu river. (1 ed.) Belém: Maurício Camargo, 197p.

CAMPBELL, T.W. 2004 Hematology of lower vertebrates. In: 55th Annual meeting of the American College of Veterinary Pathologists (ACVP) and 39th Annual meeting of the American Society of Clinical Pathology (ASVCP). ACVP and ASVCP (Eds.), Middleton WI, USA. International Veterinary Information Service, Ithaca NY. 1214p.

CARNEIRO, P.C.F.; MARTINS, M.L.; URBINATI, E.C. 2002 Effect of sodium chloride on physiological response and the gill parasite, Piscinoodinium sp., in matrinxã, Brycon cephalus (Teleostei: Characidae) subjected to transport stress. Journal of Aquaculture in the Tropics, 17(4): 337-348

CHAO, N.L. 2001 The fishery diversity and conservation of ornamental fishes in the Rio Negro Basin, Brasil: A review of Project Piaba (1989 - 1999). In: CHAO, N.L.; PETRY, P.; 
PRANG, G.; SONNENSCHEIN, L.; TLUSTY, M.T. eds: Conservation and management of ornamental fish resources of the Rio Negro Basin, Amazonia Brasil - Project Piaba. Editora da Universidade do Amazonas, Manaus. p. 161-204.

CHAO, N.L; PETRY, P.; DOWD, S.A. 2001 manutenção e o desenvolvimento sustentável da pescaria de peixes ornamentais na bacia do médio Rio Negro, Amazonas, Brasil. Projeto PIABA: Relatórios e Informes, Manaus-AM, 14p.

EL-SAYED, Y.S; SAAD, T.T; EL-BAHR, S.M. 2007 Acute intoxication o deltamethrin in monosex Nile tilapia, Oreochromis niloticusi with special reference to the clinical biochemical and haematological effects. Environmental Toxicology Pharmacology, 24(3): 212-217.

FUJIMOTO, R.Y.; CASTRO, M.P.; MARTINS, M.L.; MOARES, F.R.; MONFORT, K.C.F. 2007 Parâmetros sangüíneos de pacu Piaractus mesopotamicus (Holmberg,1887) alimentados com dietas suplementadas com cromo trivalente em duas densidades de estocagem. Acta Scientiarum Animal Sciences, 29(4): 465-471.

GOLDENFARB, P.B.; BOWYER, F.P.; HALL, E.; BROUSIUS, E. 1971 Reproducibility in the hematology laboratory: the microhematocrit determination. American Journal of Clinical Pathology, 56(1): 35-39.

GOMES, L.C.; ARAÚJO-LIMA, C.A.R.M.; ROUBACH, R.; CHIPPARI-GOMES, A.R.; LOPE, N.P.; URBINATI, E.C. 2003 Effect of fish density during transportation on stress and mortality of juvenile tambaqui Colossoma macropomum. Journal of the World Aquaculture society, 34(1): 76-84.

HOUSTON, A.H.; DOBRIC, N.; KAHURANANGA, R. 1996 The nature of hematological response in fish. Fish Physiology and Biochemistry, 15(4): 339347.

IBAMA- Instituto Brasileiro do Meio Ambiente e dos Recursos Naturais Renováveis. 2008 Diagnóstico geral das práticas de controle ligadas a exploração, captura, comercialização, exportação e uso de peixes para fins ornamentais e de aquariofilia. Brasília, versão revisada, agosto, $217 \mathrm{p}$.

LIM, L.C.; DHERT, P.; SORGELOOS, P. 2003 Recent developments and improvements in ornamental fish packaging systems for air transport. Aquaculture Research, 34(11): 923-935.

MARTINS, M.L.; MORAES, F.R.; FUJIMOTO, R.Y.; NOMURA, D.T.; FENERICK-JR, J. 2002 Respostas do híbrido tambacu (Piaractus mesopotamicus Holmberg, 1887 macho $\mathrm{x}$ Colossoma macropomum Cuvier, 1818 fêmea) a estímulos simples ou consecutivos de captura. Boletim Instituto de Pesca, 28(2): 195-204.

MOMMSEN, T.P.; VIJAYAN, M.M.; MOON, T.W. 1999 Cortisol in teleosts: dynamics, mechanisms of action, and metabolic regulation. Reviews in Fish Biology Fish, 9(3): 211-268.

PIMPÃO, C.T. 2006 Avaliação aguda dos efeitos toxicológicos da deltametrina em uma espécie de peixe fluvial nativo: estudo bioquímico e imunológico. Curitiba. 102f. (Tese de doutorado, Universidade Federal do Paraná). Disponivel em: http://dspace.c3sl.ufpr.br/dspace/bitstream/h andle/1884/10958/CL\%C1UDIA\%20TURRA\%2 0PIMP\%C3O.pdf?sequence=1. Acesso em: 05 janeiro 2014.

PRANG, G. 2001 Aviamento and the ornamental fishery of the Rio Negro, Brazil: implications for sustainable resource use. In: CHAO, N.L.; PETRY, P.; PRANG, G.; SONNENSCHEIN, L.; TLUSTY, M.T. (Eds.). Conservation and management of ornamental fish resources of the Rio Negro Basin, Amazonia, Brazil: Project Piaba. Manaus: Universidade do Amazonas, 2001. p. 43-73.

RANZANI-PAIVA, M.J.T.; SILVA-SOUZA, A.T. 2004 Hematologia de peixes brasileiros. In: RANZANI-PAIVA, M.J.T.; TAKEMOTO, R.M.; LIZAMA, M.; DE LOS A.P. Sanidade de Organismos Aquáticos. Editora Varela. São Paulo. p. 89-120.

RIBEIRO, F.A.S.; CARVALHO-JUNIOR, J.R.; FERNANDES, J.B.K.; NAKAYAMA, L. 2008 Comércio brasileiro de peixes ornamentais. Panorama da Aquicultura, 18(110): 54-59.

ROSENFELD, G. 1947 Corante pancrômico para hematologia e citologia clínica: nova combinação dos componentes do May-Grunwald e do Giemsa num só corante de emprego rápido. Memórias Instituto Butantan, 20(1): 329-334. 
SALARO, A.L.; LUIZ, R.K.; NOGUEIRA, G.C.C.B.; REIS, A.; SAKABE, R.; LAMBERTUCCI, D.M. 2003 Diferentes densidades de estocagem na produção de alevinos de trairão (Hoplias cf. lacerdae). Revista Brasileira Zootecnia, 32(5): 10331036.

SCHALCH, S.H.C.; BELO, M.A.A.; SOARES, V.E.; MORAES, J.R.E.; MORAES, F.R. 2005 Eficácia do diflubenzuron no controle de Dolops carvalhoi (Crustacea: Branchiura) em jovens pacus Piaractus mesopotamicus (Osteichthyes: Characidae) naturalmente infectados. Acta Scientiarum Animal Sciences, 27(2): 297-302.

SILVEIRA-COFFIGNY, R.; PRIETO-TRUJILLO, A.; ASCENCIO-VALLE, F. 2004 Effects of different stressors in haematological variables in cultured Oreochromis aureus S. Comparative Biochemistry and Physiology, 139(4): 245-250.

TAVARES-DIAS, M.; MORAES, F.R. 2004 Hematologia de peixes teleósteos. Ed. Ribeirão Preto, São Paulo, 144p.

TAVARES-DIAS, M.; MORAES, F.R. 2006 Hematological parameters for the Brycon orbignyanus Valenciennes, 1850 (Osteichthyes, Characidae) intensively bred. Hidrobiológica, 16(3): 271-274.

TAVARES-DIAS, M.; SANDRIN, E.F.S.; MORAES, F.R.; CARNEIRO, P.C.F. 2001 Physiological Response of "Tambaqui" Colossoma macropomum (Characidae) to Acute Stress. Boletim do Instituto de Pesca, 27(1): 43-48.

TORRES, M.F. 2007 A Pesca Ornamental na Bacia do Rio Guamá: Sustentabilidade e Perspectivas ao manejo. Belém-PA. 264f. (Tese de doutoradoNúcleo de Altos Estudos Amazônicos - NAEA, Universidade Federal do Pará). Disponível em: <http://www.naea.ufpa.br/naea/novosite/ind ex.php?action=Tcc.arquivo\&id=141>. Acesso em: 09 nov. 2013.

TORRES, M.F.; GIARIZZO, T.; CARVALHO, J.R. 2008 Diagnóstico, Tendência, Análise e Políticas Públicas para o Desenvolvimento da Pesca Ornamental no Estado do Pará. Belém-PA, SEPAq. 41f. Disponível em: $<$ http://www.sepaq.pa.gov.br/files/u1/pesca.s $\mathrm{wf}>$.
URBINATI, E.C.; CARNEIRO, P.C.F. 2001 Metabolic and hormonal responses of matrixã, Bricon cephalus (Teleost: Characidae) to transport stress under influence benzocaine. Journal of Aquaculture Tropics, 16(1): 75-85.

URBINATI, E.C.; CARNEIRO, P.C.F. 2004 Prática de manejo e estresse dos peixes em piscicultura intensiva. In: CYRINO, J.E,P.; URBINATI, E.C.; CASTAGNOLLI, N. (Eds.). Tópicos Especiais em Piscicultura de Água Doce Tropical Intensiva. Sociedade Brasileira de Aquicultura e Biologia Aquática. São Paulo. Editora TecArt. p. 171-193.

VALLADA, E.P. 1999 Manual de Técnicas Hematológicas. São Paulo. Editora Atheneu. 104p.

WENDELAAR-BONGA， S.E. 1997 The stress response in fish. Physiological Reviews, 77(3): 591625

WINKALER, E.U.; SILVA, A.G.; GALINDO H.C.; MARTINEZ, C.B.R. 2001 Biomarcadores histológicos e fisiológicos para o monitoramento da saúde de peixes de ribeirões de Londrina, Estado do Paraná. Acta Scientiarum Animal Sciences, 23(2): 507-514. 